\title{
The kidney in diabetes: dynamic pathways of injury and repair. The Camillo Golgi Lecture 2007
}

\author{
P. Fioretto • M. L. Caramori • M. Mauer
}

Received: 14 January 2008 / Accepted: 17 April 2008 /Published online: 5 June 2008

(C) Springer-Verlag 2008

\begin{abstract}
Diabetic nephropathy is the most common cause of end-stage renal disease (ESRD). The natural history of diabetic nephropathy has changed over the last decades, as a consequence of better metabolic and blood pressure management. Thus, it may now be possible to delay or halt the progression towards ESRD in patients with overt diabetic nephropathy, and the decline of renal function is not always inexorable and unavoidable. Also, the rate of progression from microalbuminuria to overt nephropathy is much lower than originally estimated in the early $80 \mathrm{~s}$. Furthermore, there is now evidence that it is possible, in humans, to obtain reversal of the established lesions of diabetic nephropathy. This review focuses on the contribution of kidney biopsy studies to the understanding of the pathogenesis and natural history of diabetic nephropathy and the identification of patients at high risk of progression to ESRD. The classic lesions of diabetic nephropathy and the well-established structural-functional relationships in type 1 diabetes will be briefly summarised
\end{abstract}

\author{
P. Fioretto $(\bowtie)$ \\ Department of Medical and Surgical Sciences, \\ University of Padua, \\ Via Giustininiani n.2, \\ 35128 Padua, Italy \\ e-mail: paola.fioretto@unipd.it \\ P. Fioretto \\ National Council for Research, Institute of Neurosciences, \\ Padua, Italy \\ M. L. Caramori $\cdot$ M. Mauer \\ Department of Medicine, University of Minnesota, \\ Minneapolis, MN, USA \\ M. Mauer \\ Department of Pediatrics, University of Minnesota, \\ Minneapolis, MN, USA
}

and the renal lesions leading to renal dysfunction in type 2 diabetes will be described. The relevance of these biopsy studies to diabetic nephropathy pathogenesis will be outlined. Finally, the evidence and the possible significance of reversibility of diabetic renal lesions will be discussed, as well as future directions for research in this field.

Keywords Morphometric analysis · Renal structure .

Type 1 diabetes · Type 2 diabetes
Abbreviations
DN diabetic nephropathy
ESRD end-stage renal disease
GBM glomerular basement membrane
PTA pancreas transplant alone
TBM tubular basement membrane

The changing natural history of diabetic nephropathy

Large long-term clinical trials have demonstrated that improved blood glucose [1, 2] and blood pressure [3-5] control (e.g. through use of renin-angiotensin blockers) slows the development and/or progression of diabetic nephropathy (DN). Indeed, as a result of these improvements the natural history of $\mathrm{DN}$ has changed over the last decades. Thus, it may now be possible to delay or halt progression towards end-stage renal disease (ESRD) in patients with overt DN [3-5]. This contrasts with the concept that by the time patients have overt nephropathy, the decline in renal function is inevitable.

The natural history of the disease at earlier stages may also have changed. In the early 1980s the risk of progression 
to overt proteinuria (AER $>200 \mu \mathrm{g} / \mathrm{min}$ ) in microalbuminuric (AER $20-200 \mu \mathrm{g} / \mathrm{min}$ ) type 1 diabetic patients was estimated to be about $80 \%$ over a decade [6-8]. More recently, prospective studies have demonstrated that the percentage of type 1 diabetic patients with microalbuminuria who progress to proteinuria over 10 years is only about $30 \%$ [9-13]. This apparent decrease may be due to an overestimation of risk in earlier studies, improved prognosis as a result of advancements in treatment, or a combination of the two. In fact, the concept that a substantial proportion of microalbuminuric patients spontaneously regress to normoalbuminuria is now well established [9-13]. In type 2 diabetes, the progression rate from microalbuminuria to proteinuria is similar (around 30\% in 10 years) [14]. In the Steno-2 study, during a 7.8 year follow-up of 151 microalbuminuric type 2 diabetic patients, $31 \%$ progressed to proteinuria, $31 \%$ regressed to normoalbuminuria and $38 \%$ remained microalbuminuric [15]. It is interesting that the rate of GFR decline was much lower in patients who regressed to normoalbuminuria $\left(2.3 \mathrm{ml} \mathrm{min}^{-1}\right.$ year $\left.^{-1}\right)$ than in patients who progressed to proteinuria $\left(5.4 \mathrm{ml} \mathrm{m^{-1 }}\right.$ year $\left.{ }^{-1}\right)$, suggesting that regression to normoalbuminuria is associated with preservation of renal function [15].

We have demonstrated that prolonged euglycaemia, achieved through pancreas transplantation, leads to reversal of established lesions of DN in patients with type 1 diabetes [16]. These findings contradict the long-held belief that the lesions of DN are irreversible, and further contribute to the changing natural history of DN.

\section{Pathways of injury}

\section{Renal lesions in type 1 diabetes}

In type 1 diabetic patients, glomerulopathy is characterised by thickening of the glomerular basement membrane (GBM) and mesangial expansion, leading to a progressive reduction in the filtration surface of the glomerulus $[17,18]$ (Fig. 1). Although the most important structural changes occur in the glomeruli $[17,18]$, concomitantly and approximately in proportion to the degree of glomerulopathy, the arterioles [19], tubules [20] and interstitium [21] also develop morphological lesions. Thus, these extraglomerular lesions usually become severe only in the presence of advanced glomerulopathy, typically in patients with overt proteinuria and/or decreasing GFR.

The first changes that can be measured are thickening of the GBM and tubular basement membrane (TBM) [22]. Within few years after the onset of diabetes, afferent and efferent arteriolar hyalinosis can also be noted. Mesangial expansion can be detected in some patients as early as 5-7 years after diabetes onset [17], and when diffuse and

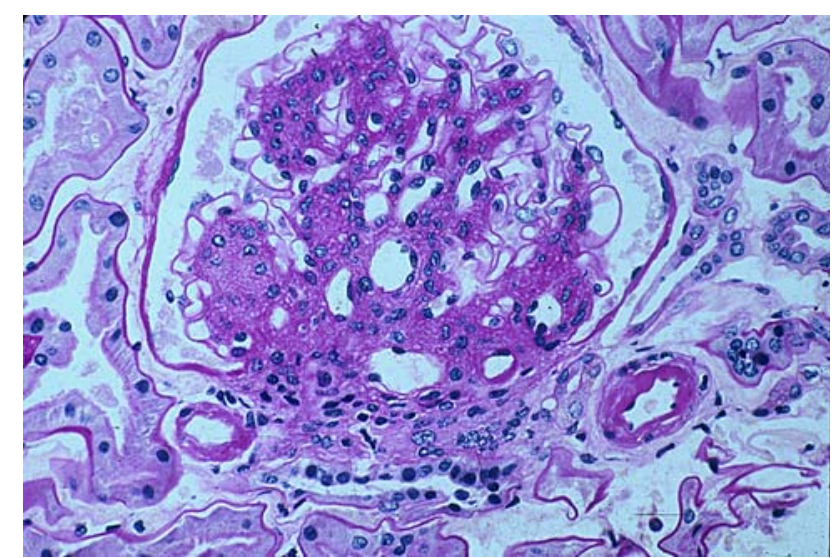

Fig. 1 Glomerulus from a type 1 diabetic patient with diffuse and nodular mesangial expansion, glomerular basement membrane (GBM) thickening and afferent and efferent arteriolar hyalinosis (periodic acid-Schiff stain). Reprinted from [18]

generalised is termed diffuse diabetic glomerulosclerosis. Nodular glomerulosclerosis consists of areas of marked mesangial expansion forming large, round, fibrillar mesangial zones with palisading of mesangial nuclei (KimmelstielWilson nodules). Additional abnormalities include global glomerular sclerosis [23] and interstitial expansion [21]. More recently, we reported that the onset of proteinuria is associated with the development of new glomerular lesions, specifically, widespread abnormalities of the junction of the proximal tubule with the glomerulus, which ultimately lead to separation of the glomerulus from its tubule (atubular glomeruli) and, thus, loss of glomerular function [24, 25].

Studies of the relationships between structural and functional parameters have demonstrated that the critical lesion of DN, leading to progressive loss of renal function, is mesangial expansion [17]. However, in advanced stages of the disease, interstitial, tubular and glomerulo-tubular junction injuries drive the progression towards ESRD [24, 25].

We have studied glomerular structure in a large cohort of long-standing type 1 diabetic patients with AER levels ranging from normoalbuminuria to high levels of microalbuminuria [26]. All variables of glomerulopathy were, on average, abnormal in the normoalbuminuric group, although approximately half of the patients had normal structure. No patients with an AER of $>30 \mu \mathrm{g} / \mathrm{min}$ had normal glomerular structure [26]. Interestingly, in several normoalbuminuric patients, the severity of glomerulopathy overlapped with that in patients with high levels of microalbuminuria [26]. It is tempting to hypothesise that normoalbuminuric patients with more advanced lesions have an increased risk of progressing to microalbuminuria and proteinuria, and our published [27] and unpublished data support this view. In contrast, patients with an increased AER but glomerular parameters near the normal range are more likely to revert to normoalbuminuria. Although an increase in AER in the microalbuminuric range is usually the first clinical expres- 
sion of DN, in some long-term type 1 diabetic patients this is instead a reduced GFR [28]. We have observed that a subset of long-term normoalbuminuric type 1 diabetic patients, most often women with diabetic retinopathy and/or hypertension, may still be normoalbuminuric despite having a reduced GFR $\left(<90 \mathrm{ml} \mathrm{min}^{-1} 1.73 \mathrm{~m}^{-2}\right)$ [28]. These patients have more advanced glomerulopathy lesions than those with normoalbuminuria and a normal GFR. These findings have been confirmed, especially in type 2 diabetes, where this condition has been termed 'normoalbuminuric renal insufficiency' [29].

\section{Renal lesions in type 2 diabetes}

The majority of studies on renal structure in diabetes have been performed in patients with type 1 diabetes, and assumptions have been made that renal pathology in type 2 diabetes is the same as in type 1 diabetes. However, renal lesions in type 2 diabetes are much more complex. First, in contrast with type 1 diabetes, the prevalence of non-diabetic renal lesions in proteinuric type 2 diabetic patients has been reported to be high (approximately 30\%) [30, 31]. However, a much lower occurrence of non-diabetic renal disease $(12 \%)$ was reported in a series of 33 proteinuric patients [32]. This broad variability is likely to be related to different criteria adopted from clinic to clinic for kidney biopsy indications [33]. We performed a large number of research kidney biopsies in patients with type 2 diabetes, and found that $<10 \%$ of the proteinuric patients had nondiabetic renal diseases. However, we have described marked heterogeneity in renal structure in these patients [34]. Indeed, only a minority had histopathological patterns resembling those typically present in type 1 diabetes. The remainder had very mild or absent diabetic glomerulopathy with or without tubulo-interstitial, arteriolar and global glomerulosclerosis changes. Based on these findings we proposed a classification system that included three major categories [34]:

1. Category I: Normal or near-normal renal structure. These patients $(35 \%$ of those with microalbuminuria and $10 \%$ of those with proteinuria) had biopsies that were normal or showed very mild lesions (Fig. 2a).

2. Category II: Typical diabetic nephropathology. These patients $(30 \%$ of those with microalbuminuria and $55 \%$ of those with proteinuria) had established diabetic lesions with an approximately balanced severity of glomerular, tubulo-interstitial and arteriolar changes. This picture is typical of that seen in type 1 diabetes (Fig. 1).

3. Category III: Atypical patterns of renal injury. These patients $(35 \%$ of those with microalbuminuria and proteinuria) had relatively mild glomerular diabetic changes considering the disproportionately severe changes in other renal structures, including tubular atrophy, TBM thickening and reduplication, interstitial fibrosis (Fig. 2b), advanced glomerular arteriolar hyalinosis commonly associated with atherosclerosis of larger vessels, and global glomerular sclerosis. These findings have been confirmed by electron microscopy studies, as discussed below.

Thus, the renal lesions leading to renal dysfunction differ in type 2 and type 1 diabetes. The tubulo-interstitial and vascular changes are likely to be related not only to hyperglycaemia, but also to ageing, atherosclerosis and systemic hypertension, which often pre-dates the onset of type 2 diabetes. However, it is also possible that the heterogeneity in renal structure might reflect the heterogeneous nature of type 2 diabetes itself. Interestingly, patients with 'typical' (Category II) DN lesions had a longer known diabetes duration, worse metabolic control and they all had diabetic retinopathy (50\% background, $50 \%$ proliferative). In contrast, none of the patients in Categories I and III had proliferative retinopathy, and background retinopathy was observed only in $50 \%$ of Category I and $57 \%$ of Category III patients [34]. This suggests the possibility that the different underlying pathophysiological mechanisms responsible for type 2 diabetes in these groups of patients may also underlie different renal and retinal pathophysiological mechanisms or responses.

The heterogeneity in renal structure in patients with type 2 diabetes has important clinical implications, in that patients with different patterns of renal injury may respond differently to various therapeutic agents. Indeed, we have observed that this heterogeneity in renal structure affects renal prognosis, as patients with typical DN (Category II) have a faster GFR decline than patients with very mild glomerulopathy, with or without tubulo-interstitial and vascular lesions (Categories I and III) [35]. Extrapolating these findings to the recent natural history data in microalbuminuric type 2 diabetic patients [15], it is tempting to speculate that patients with typical diabetic glomerulopathy (Category II) are more likely to progress to overt nephropathy and experience a faster GFR loss, while patients without glomerulopathy are more likely to regress to normoalbuminuria (Category I, normal renal structure) or to remain microalbuminuric (Category III, tubulo-interstitial and/or vascular lesions) with minimal loss in renal function.

The data on structural-functional relationships in type 2 diabetes based on quantitative morphometric analysis are less abundant. In Japanese type 2 diabetic patients, morphometric measures of diabetic glomerulopathy showed correlations with renal functional parameters similar to those observed in type 1 diabetes [36]. Similar structuralfunctional relationships have also been reported in 21 white 
Fig. 2 Renal biopsies from microalbuminuric type 2 diabetic patients (periodic acid-Schiff stain). a Normal glomerular, tubular, interstitial and vascular structures. This would be classified as Category I. b Mild mesangial expansion relative to the severity of interstitial fibrosis and tubular atrophy. This would be classified as Category III. Reprinted from [34], with kind permission of Springer Science+Business Media
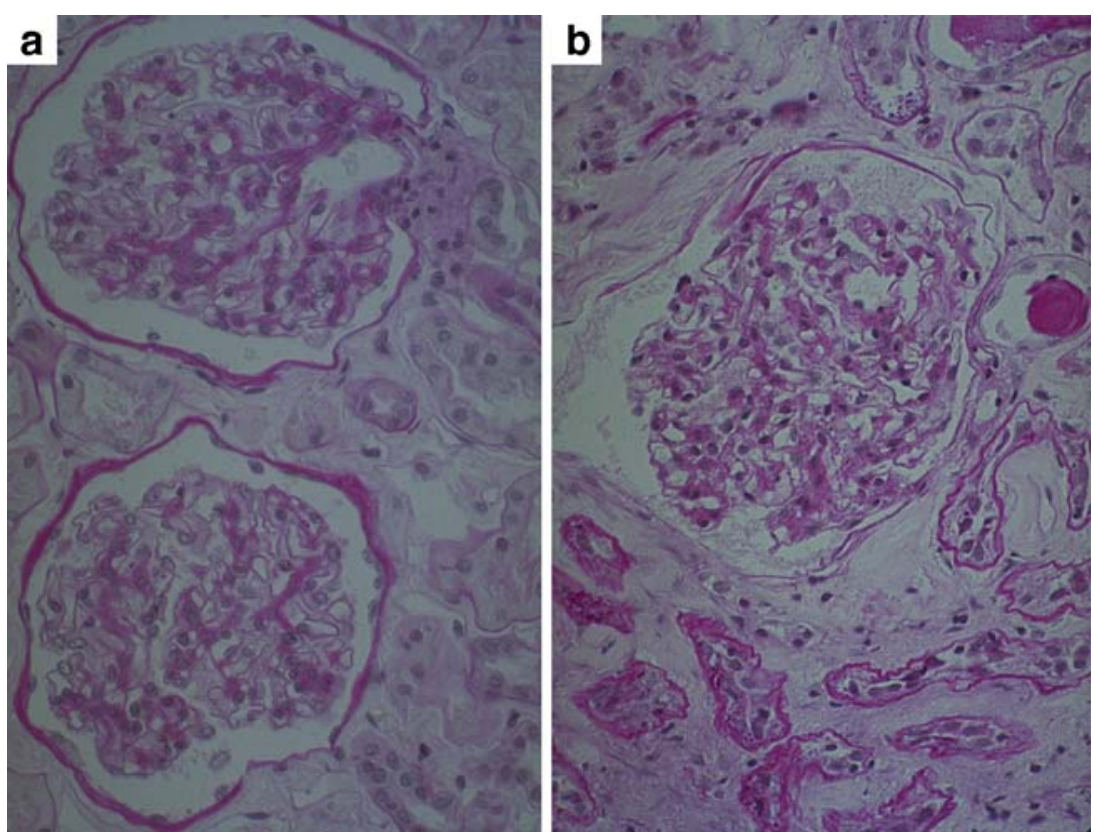

diabetic individuals with overt nephropathy [37]. In this latter study, creatinine clearance was correlated with both mesangial and interstitial expansion, suggesting an important role of interstitial lesions in determining loss of renal function in patients with advanced DN [37]. These findings differ from those of a previous study [38] on type 2 diabetic patients with overt nephropathy, which reported that, although all glomerular parameters were, on average, abnormal, some patients had normal glomerular structure. In contrast, in type 1 diabetic patients with overt nephropathy, glomerular structure was always severely altered [38]. We have analysed research kidney biopsy samples, obtained from a large group of Italian type 2 diabetic patients, using electron microscopic morphometric analysis, and found that the degree of glomerular structural lesions increased with increasing albuminuria, from normoalbuminuria to proteinuria (P. Fioretto, unpublished data). However, several patients, despite persistent microalbuminuria or proteinuria, had normal glomerular structure. Moreover, compared with type 1 diabetic patients with similar renal function, diabetic glomerulopathy was less advanced in patients with type 2 diabetes. The relationships between renal function and glomerular structural variables were significant, but less precise than in patients with type 1 diabetes. By cluster analysis, we compared the correlations between AER and morphometric measures of glomerular structure in type 1 and type 2 diabetic patients and observed that approximately one-third of type 2 diabetic patients fall outside the cluster for structural-functional relationships (of the individual structural variables) for the type 1 diabetic patients (P. Fioretto, B. Najafian, Department of Laboratory Medicine and Pathology, University of Minnesota, unpublished data). This is because a substantial proportion of type 2 diabetic patients have an increased AER, despite the paucity of diabetic glomerulopathy lesions. These findings largely confirm our initial description, by light microscopy, of heterogeneity in renal structure among patients with type 2 diabetes and an increased AER [34]. Although the prognostic relevance of falling outside the cluster has yet to be fully described, we have reported that the rate of GFR decline was significantly correlated with the severity of diabetic glomerulopathy lesions in a large cohort of type 2 diabetic patients, who underwent precise GFR determinations over a follow-up period of 4 years [35].

Thus, renal lesions different from those typical of diabetic glomerulopathy should be considered when investigating the nature of an abnormal AER in type 2 diabetes. These lesions include changes in the structure of renal tubules, interstitium, arterioles and, within the glomeruli, podocytes.

Pima Indians with type 2 diabetes and proteinuria have fewer podocytes per glomerulus than those without nephropathy [39]. Also, over a 4 year follow-up period, a lower number of podocytes per glomerulus at baseline was the strongest predictor of greater increases in AER and a higher risk of progression to overt nephropathy in microalbuminuric patients [40]. These observations suggest that podocyte loss is important in the progression to overt nephropathy, rather than in its genesis and early development.

In a cohort of 67 type 2 diabetic patients with AER values ranging from normoalbuminuria to proteinuria [41], the density of podocytes per glomerulus was significantly decreased in all diabetic patients compared with controls, and it was lower in microalbuminuric and proteinuric patients than in normoalbuminuric patients. The absolute number of podocytes per glomerulus was also lower in 
microalbuminuric and proteinuric patients compared with controls; however, only the density was significantly correlated with AER. In addition, microalbuminuric and proteinuric patients had increased foot process width compared with normoalbuminuric patients, and this was directly related to AER. Decreased density and number of podocytes and increased foot process width have also been described in 16 type 2 diabetic patients with nephropathy (median proteinuria $570 \mathrm{mg} / 24 \mathrm{~h}$ ) compared with normal controls [42].

These results suggest that, in white type 2 diabetic patients, changes in podocyte structure and density occur in the early stages of DN and might contribute to increasing albuminuria in these patients. Moreover, podocyte structural changes could in part explain abnormal albuminuria in patients without diabetic glomerulopathy [41]. Podocytes probably have a limited capacity for replication, such that when they are lost they cannot be easily replaced by new cells. Thus, the loss of podocytes, together with the increase in glomerular volume caused by diabetes, necessarily require the residual cells to cover a larger area of GBM. This could cause foot process widening and detachment, resulting in bare GBM areas with consequent proteinuria. Moreover, these areas of detachment could initiate adhesions and be potential starting points for abnormalities in glomerulo-tubular junctions and focal or global glomerular sclerosis.

\section{Pathways of repair: reversal of diabetic renal injury}

The lesions of DN have been considered to be irreversible. If reversal is possible, this should happen during long-term normoglycaemia, which is currently achievable only by pancreas transplantation. This procedure, performed in uraemic patients at the time of renal transplant or, less frequently, after kidney transplant, prevents or slows the development of early diabetic glomerulopathy lesions in the renal allograft $[43,44]$.

We have studied 13 recipients of pancreas transplantation alone (PTA) and found that, despite 5 years of normoglycaemia, the lesions of DN were unaffected [45]. At 10 years post-PTA, eight patients were available for follow-up studies [16]; at this time, reversal of diabetic glomerular and tubular lesions was obvious in all eight patients [16]. By light microscopy, a remarkable amelioration of glomerular structure was evident, including total disappearance of Kimmelstiel-Wilson nodular lesions (Fig. 3). Thus, GBM and TBM widths and mesangium fractional volume were decreased at the 10 year follow-up, returning to normal values in most patients (Fig. 4). Additional patients have now been studied at 5 and 10 years after PTA, and we can confirm that glomerular lesions remained unchanged at
5 years but showed a clear improvement and healing at 10 years. The worsening of interstitial fibrosis and tubular atrophy observed at 5 years post-PTA (Fig. 5a,b) [46], likely consequent to ciclosporin therapy, was reversed at 10 years post-PTA (Fig. 5c) [47]. We observed remodelling of the tubulo-interstitial lesions in the 10 year vs the 5 year biopsy samples, with decreases in the cortical interstitial fractional volume and the fractional volume of tubules that were atrophic and an overall decrease in renal interstitial fibrillar collagen [47]. These tubulo-interstitial structural improvements might be attributable to prolonged normoglycaemia (probably also in association with the restoration of C-peptide secretion), decreased cyclosporine dose or both. The reasons for the long delay in the reversal of DN lesions are unknown. Nevertheless, the long time necessary for these diabetic lesions to disappear is consistent with their slow rate of development. Regardless of the mechanisms involved, at some point after PTA, glomerular, tubular and interstitial cells changed their behaviour towards extra cellular matrix (ECM) removal and architectural remodelling, demonstrating the remarkable ability of the kidney to recover from injury and heal. The understanding of the molecular and cellular mechanisms involved in these repair processes could provide new directions for the treatment of DN.

Other therapeutic approaches, such as antihypertensive agents, as discussed below, have not been described to lead to amelioration or reversal of diabetic renal lesions.

\section{Where should we go from here?}

Since interventions at later stages of DN may slow but not always prevent progression to ESRD, improved primary prevention strategies are needed. These will require a more complete understanding of the pathogenesis of early diabetic renal injury in addition to improved predictors of DN risk.

We have previously argued that AER levels within the so-called 'normoalbuminuric' range, together with currently available risk factors, such as family history, ambulatory blood pressure measurements, retinopathy evaluations, glycaemic and lipid levels, may allow earlier risk profiling than the dichotomisation of patients into the categories of 'normoalbuminuria' and 'microalbuminuria' [11]. In addition, increased precision of risk prediction would be helpful among microalbuminuric patients. New, more accurate, means of defining early risk would not only help select those patients who would benefit from more aggressive treatment with currently available modalities, but would also likely provide pathogenetic insights leading to new treatment options. Kidney biopsy studies are crucial in the search for new early and specific predictors, such as blood or urinary biomarkers. Indeed, early markers/predictors can 


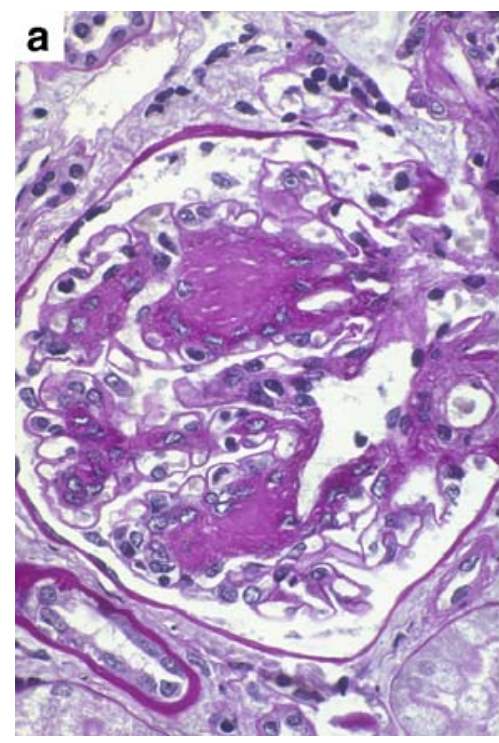

Fig. 3 a Diffuse and nodular mesangial expansion in a type 1 diabetic patient prior to pancreas transplant alone (PTA). b Persistence of diffuse and nodular mesangial expansion 5 years after successful PTA in the same patient shown in a. c Marked reduction of mesangial

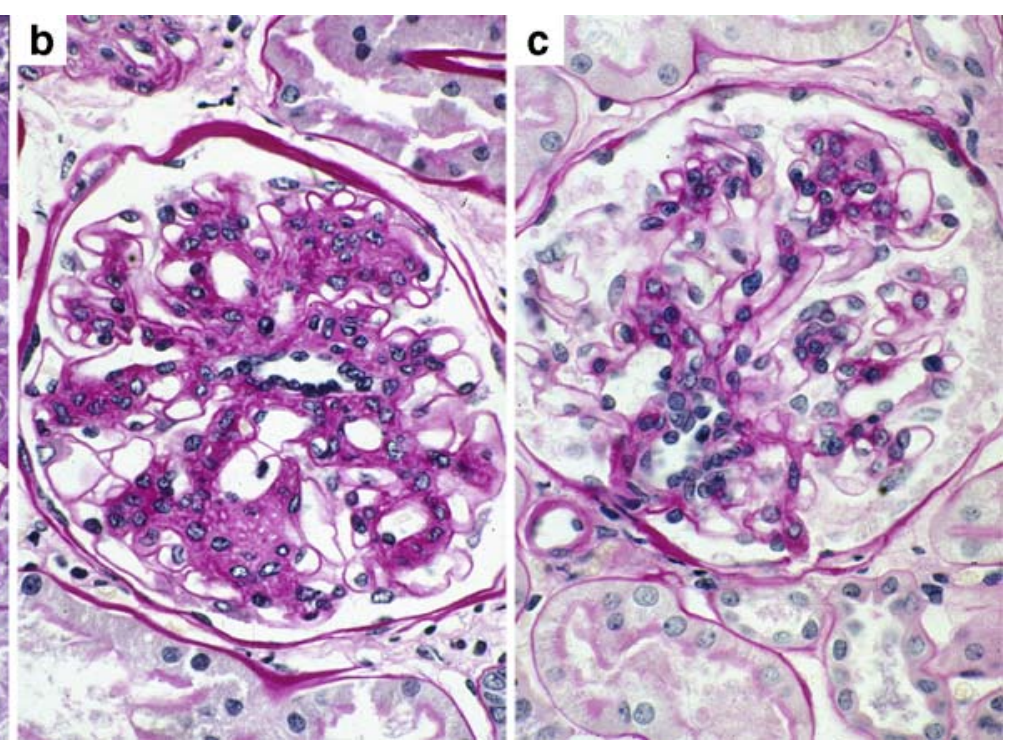

expansion 10 years after successful PTA in the same patient shown in panels $\mathbf{a}$ and $\mathbf{b}$. All sections stained with periodic acid-Schiff stain. Reprinted with permission from [16]. Copyright (C) 1998 Massachusetts Medical Society. All rights reserved

markers associated with glomerular vs tubulo-interstitial lesions would allow better definition of the phenotype of type 2 diabetic patients for genetic studies and clinical trials.

Genetic predisposition to $\mathrm{DN}$ has been strongly suggested in multiple cross-sectional studies in type 1 [48-50] and type 2 diabetic [51,52] siblings concordant for diabetes. Importantly, diabetic sibling pairs, known to be concordant for DN risk, are highly concordant for diabetic glomerulopathy lesions [53]. This risk seems to be substantial, in part independent of glycaemia [54]. There are ongoing searches for genetic loci related to DN susceptibility through genomic scanning and candidate gene approaches, although neither approach has yet yielded definitive results [55]. Genetic polymorphisms in candidate genes have been evaluated in several studies; the most extensively studied genes are perhaps those in the renin-angiotensin system. Several other genes have been studied, and a couple have been given special attention lately. A leucine repeat in the gene encoding carnosinase was associated with $\mathrm{DN}$ in both type 1 and type 2 diabetic patients [56, 57]. Multiple variations in the gene encoding superoxide dismutase 1 were significantly associated with persistent microalbuminuria and severe nephropathy in the DCCT/Epidemiology of Diabetes Interventions and Complications (EDIC) study [58]. In the Family Investigation of Nephropathy and Diabetes (FIND) study, genome-wide scan demonstrated multiple chromosomal regions linked to estimated GFR in multiethnic families ascertained by a proband with DN [59]. In our view, the research renal biopsy is an important tool in genetic studies that allows precise definition of the renal phenotype; this is particularly relevant for patients with type 2 diabetes, as discussed above. 


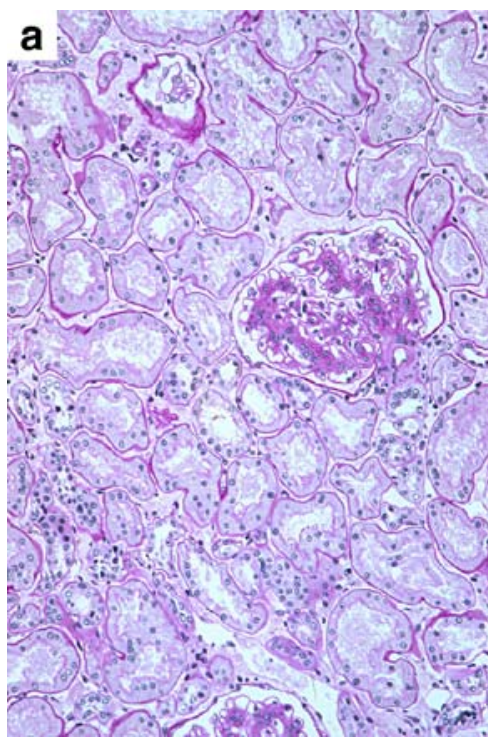

Fig. 5 a Moderate to advanced diabetic glomerulopathy with near normal tubules and interstitium in this type 1 diabetic patient prior to PTA. b Persistence of the diabetic glomerulopathy changes and de novo interstitial fibrosis and tubular atrophy 5 years after PTA in the same patient shown in panel a. Reprinted from [47]. c Near

Clinical trials have clearly demonstrated that antihypertensive therapy, especially with RAS blockade, is effective in slowing progression of DN [3-5]. Also, multifactorial intervention strongly reduces the risk of progressing to overt nephropathy and ESRD [60]

Dual blockade, using ACE inhibitors and angiotensin receptor blockers, and the use of anti-aldosterone agents and renin blockers are promising treatment options. However, to date, only short-term studies on the effects on AER are available. Studies of the effect of RAS blockade on renal structure so far have been largely underpowered (small numbers, short duration of follow-up). Thus, in a small group of 54 normotensive ( $\mathrm{BP}<150 / 90 \mathrm{mmHg}$ ) type 1 diabetic patients with an AER of between 30 and $1500 \mu \mathrm{g} / \mathrm{min}$, ACE inhibitor therapy (enalapril) for 3 years did not affect glomerular or interstitial structures [61]. Indeed, there was no change over this time interval in any structural parameter in the enalapril, nifedipine or placebo groups. Another study compared renal structure before and after 38 months of treatment with enalapril or metoprolol in 13 type 1 diabetic patients with microalbuminuria [62], reporting no change over time in either group. In 19 type 2 diabetic patients, 2 years of treatment with perindopril prevented the progression of interstitial fibrosis compared with controls [63], without affecting glomerular structure. Thus, RAS blockade, effective in postponing ESRD, has not so far been shown to have a favourable effect on renal structure. In particular, in the studies above, there was no evidence of an improvement or reversal of DN lesions.

A wide variety of possible treatments that could prevent DN injury or speed repair have been suggested from rodent studies, including inhibition of NADPH oxidase assembly by apocynin [64], administration of the AGE crosslink breaker, alagebrium [65], and many others, beyond the scope of this review. However, extrapolation from rodent studies to humans is fraught with difficulties, and new drug testing is problematic (see below). For example, protein kinase $\mathrm{C}$ inhibition by ruboxistaurin showed some promise in reducing albuminuria and sustaining GFR in proteinuric type 2 diabetic patients after 1 year of treatment [66], but is not currently being actively pursued; an indication of the critical research challenges in this area.

Thus, as clearly demonstrated by the studies performed to date [61-63], clinical trials using renal structure as an endpoint, especially in the early stages of $\mathrm{DN}$, require large numbers and, most importantly, a long follow-up duration (likely $7-10$ years). This would require the cooperation of industries and national funding agencies, along with strong commitment from the investigators and patients.

The pancreas transplant studies clearly demonstrated truly remarkable capabilities for renal glomerular and tubulo-interstitial healing and remodelling in the human kidney. One can now envision diabetic glomerulopathy as the expression of a long-standing imbalance between processes of injury and repair. If this is indeed the case, then research, heretofore almost entirely focused on understanding mechanisms of renal injury in diabetes, should broaden its horizons to include studies on repair. Teleologically, the cells of the glomerulus must sense their abnormal ECM environment and architectural distortion and have the cellular mechanisms necessary to engineer ECM removal that exceeds production. This represents scar-free healing 
[67], a striking characteristic of early fetal life. As the capability for liver regeneration makes clear [68], there are time-specific variations in regeneration capacity in humans. In addition, the healing capacities may be influenced by the inflammatory responses [69]. Newer high-throughput research tools [67] applied to this area could improve our understanding of healing processes, which may use signalling pathways similar to those involved in the original injury [70]. Thus, subtle manipulations of these injury/repair processes could lead to major benefits in terms of disease prevention and treatment.

Acknowledgements P. Fioretto was a recipient of a Juvenile Diabetes Research Foundation International (JDRFI) Research Fellowship grant and a Career Development Award. M. L. Caramori was previously supported by a JDRFI Research Fellowship grant and is currently the recipient of a JDRFI Career Development Award. This work was supported in part by grants from the Italian Ministry of Health (RF 2001-2005) and the Italian Ministry of University and Research (FIRB 2002-2006), the National Institutes of Health (DK 13083, DK 54638 and DK 51975), and the National Center for Research Resources (M01-RR00400). We are most grateful to all of the patients who volunteered for these studies and to our many collaborators, technicians and clinical research coordinators who were critical to these studies.

Duality of interest The authors declare that there is no duality of interest associated with this manuscript.

\section{References}

1. The DCCT Research Group (1993) The effect of intensive treatment of diabetes mellitus on the development and progression of long-term complications in insulin-dependent diabetes mellitus. N Engl J Med 329:977-986

2. UK Prospective Diabetes Study (UKPDS) Group (1998) Intensive blood glucose control with sulphonylureas or insulin compared with conventional treatment and risk of complications in patients with type 2 diabetes (UKPDS 33). Lancet 352:837-853

3. Lewis EJ, Hunsicker LG, Bain RP et al (1993) The effect of angiotensin-converting-enzyme inhibition on diabetic nephropathy. The Collaborative Study Group. N Engl J Med 329:1456-1462

4. Lewis EJ, Hunsicker LG, Clarke WR, Collaborative Study Group et al (2001) Renoprotective effect of the angiotensin-receptor antagonist irbesartan in patients with nephropathy due to type 2 diabetes. N Engl J Med 345:851-860

5. Brenner BM, Cooper ME, de Zeeuw D, RENAAL Study Investigators et al (2001) Effects of losartan on renal and cardiovascular outcomes in patients with type 2 diabetes and nephropathy. N Engl J Med 345:861-869

6. Viberti GC, Hill RD, Jarrett RJ, Argyropoulos A, Mahmud U, Keen H (1982) Microalbuminuria as a predictor of clinical nephropathy in insulin-dependent diabetes mellitus. Lancet 1:1430-1432

7. Parving H-H, Oxenbøll B, Svendsen PA, Christiansen JS, Andersen AR (1982) Early detection of patients at risk of developing diabetic nephropathy: a longitudinal study of urinary albumin excretion. Acta Endocrinol (Copenh) 100:550-552

8. Mogensen CE, Christensen CK (1984) Predicting diabetic nephropathy in insulin-dependent diabetic patients. N Engl J Med 311:89-93
9. Forsblom CM, Groop P-H, Ekstrand A, Groop LC (1992) Predictive value of microalbuminuria in patients with insulin dependent diabetes of long duration. BMJ 305:1051-1053

10. Caramori ML, Fioretto P, Mauer M (2000) The need for early predictors of diabetic nephropathy risk: is albumin excretion rate sufficient? Diabetes 49:1399-1408

11. Caramori ML, Fioretto P, Mauer M (2006) Enhancing the predictive value of urinary albumin for diabetic nephropathy. J Am Soc Nephrol 17:339-352

12. Perkins BA, Ficociello LH, Silva KH, Finkelstein DM, Warram JH, Krolewski AS (2003) Regression of microalbuminuria in type 1 diabetes. N Engl J Med 348:2285-2293

13. Hovind P, Tarnow L, Rossing P et al (2004) Predictors for the development of microalbuminuria and macroalbuminuria in patients with type 1 diabetes: inception cohort study. BMJ 328: $1105-1119$

14. Adler AI, Stevens RJ, Manley SE, Bilous RW, Cull CA, Holman RR (2003) Development and progression of nephropathy in type 2 diabetes: the United Kingdom Prospective Diabetes Study (UKPDS 64). Kidney Int 63:225-232

15. Gaede P, Tarnow L, Vedel P, Parving HH, Pedersen O (2004) Remission to normoalbuminuria during multifactorial treatment preserves kidney function in patients with type 2 diabetes and microalbuminuria. Nephrol Dial Transplant 19:2784-2788

16. Fioretto P, Steffes MW, Sutherland DE, Goetz FC, Mauer M (1998) Reversal of lesions of diabetic nephropathy after pancreas transplantation. N Engl J Med 339:69-75

17. Mauer SM, Steffes MW, Ellis EN et al (1984) Structural functional relationships in diabetic nephropathy. J Clin Invest 74:1143-1155

18. Fioretto P, Mauer M (2007) Histopathology of diabetic nephropathy. Semin Nephrol 27:195-207

19. Bell ET (1953) Renal vascular disease in diabetes mellitus. Diabetes 2:376-389

20. Brito P, Fioretto P, Drummond K, Kim Y et al (1998) Proximal tubular basement membrane width in insulin-dependent diabetes mellitus. Kidney Int 53:754-761

21. Lane PH, Steffes MW, Fioretto P, Mauer M (1993) Renal interstitial expansion in insulin-dependent diabetes mellitus. Kidney Int 43:661-667

22. Østerby R (1972) Morphometric studies of the peripheral glomerular basement membrane in early juvenile diabetes I. Development of initial basement membrane thickening. Diabetologia 8:84-92

23. Harris RD, Steffes MW, Bilous RW et al (1991) Global glomerular sclerosis and glomerular arteriolar hyalinosis in insulin-dependent diabetes. Kidney Int 40:107-114

24. Najafian B, Kim Y, Crosson JT et al (2003) Atubular glomeruli and glomerulotubular junction abnormalities in diabetic nephropathy. J Am Soc Nephrol 14:908-917

25. Najafian B, Crosson JT, Kim Y et al (2006) Glomerulotubular junction abnormalities are associated with proteinuria in type 1 diabetes. J Am Soc Nephrol 17:S53-S60

26. Fioretto P, Steffes MW, Mauer SM (1994) Glomerular structure in non-proteinuric insulin-dependent diabetic patients with various levels of albuminuria. Diabetes 43:1358-1364

27. Steinke JM, Sinaiko AR, Kramer MS, for the International Diabetic Nephropathy Study Group et al (2005) The early natural history of nephropathy in type 1 diabetes. III. Predictors of fiveyear urinary albumin excretion rate patterns in initially normoalbuminuric patients. Diabetes 54:2164-2171

28. Caramori ML, Fioretto P, Mauer M (2003) Low glomerular filtration rate in normoalbuminuric type 1 diabetic patients: an indicator of more advanced glomerular lesions. Diabetes 52:1036-1040

29. MacIsaac RJ, Tsalamandris C, Panagiotopoulos S et al (2004) Normoalbuminuric renal insufficiency in type 2 diabetes. Diabetes Care 27:195-200 
30. Parving H-H, Gall M-A, Skøtt P et al (1992) Prevalence and causes of albuminuria in non-insulin-dependent diabetic patients. Kidney Int 41:758-762

31. Gambara V, Mecca G, Remuzzi G et al (1993) Heterogeneous nature of renal lesions in type II diabetes. J Am Soc Nephrol 3:1458-1466

32. Olsen S, Mogensen CE (1996) Non-diabetic renal disease in NIDDM proteinuric patients may be rare in biopsies from clinical practice. Diabetologia 39:1638-1645

33. Mazzucco G, Bertani T, Fortunato M (2002) Different patterns of renal damage in type 2 diabetes mellitus: a multicentric study on 393 biopsies. Am J Kidney Dis 39:713-720

34. Fioretto P, Mauer M, Brocco E et al (1996) Patterns of renal injury in type 2 (non-insulin dependent) diabetic patients with microalbuminuria. Diabetologia 39:1569-1576

35. Nosadini R, Velussi M, Brocco E et al (2000) Course of renal function in type 2 diabetic patients with abnormalities of albumin excretion rate. Diabetes 49:476-484

36. Hayashi H, Karasawa R, Inn $H$ et al (1992) An electron microscopic study of glomeruli in Japanese patients with noninsulin dependent diabetes mellitus. Kidney Int 41:749-757

37. White KE, Bilous RW (2000) Type 2 diabetic patients with nephropathy show structural-functional relationships that are similar to type 1 disease. J Am Soc Nephrol 11:1667-1673

38. Østerby R, Gall MA, Schmitz A, Nielsen FS, Nyberg G, Parving HH (1993) Glomerular structure and function in proteinuric type 2 (non insulin dependent) diabetic patients. Diabetologia 36:10641070

39. Pagtalunan ME, Miller PL, Jumping-Eagle S et al (1997) Podocyte loss and progressive glomerular injury in type 2 diabetes. J Clin Invest 99:342-348

40. Meyer TW, Bennett PH, Nelson RG (1999) Podocyte number predicts long-term urinary albumin excretion in Pima Indians with type II diabetes and microalbuminuria. Diabetologia 42:13411344

41. Dalla Vestra M, Masiero A, Roiter AM et al (2003) Is podocyte injury relevant in diabetic nephropathy? Studies in patients with type 2 diabetes. Diabetes 52:1031-1035

42. White KE, Bilous RW (2004) Structural alterations to the podocyte are related to proteinuria in type 2 diabetic patients. Nephrol Dial Transplant 19:1437-1440

43. Bohman S-O, Tyden G, Wilczek H et al (1985) Prevention of kidney graft diabetic nephropathy by pancreas transplantation in man. Diabetes 34:306-308

44. Bilous RW, Mauer SM, Sutherland DER et al (1989) The effects of pancreas transplantation on the glomerular structure of renal allografts in patients with insulin-dependent diabetes. $\mathrm{N}$ Engl J Med 32:80-85

45. Fioretto P, Mauer SM, Bilous RW, Goetz FC, Sutherland DER, Steffes MW (1993) Effects of pancreas transplantation on glomerular structure in insulin-dependent diabetic patients with their own kidneys. Lancet 342:1193-1196

46. Fioretto P, Steffes MW, Mihach MJ, Strom EJ, Sutherland DER, Mauer M (1995) Cyclosporine associated lesions in native kidneys of diabetic pancreas transplant recipients. Kidney Int 48:489-495

47. Fioretto P, Sutherland DER, Najafian B, Mauer M (2006) Remodeling of renal interstitial and tubular lesions in pancreas transplant recipients. Kidney Int 69:907-912

48. Seaquist ER, Goetz FC, Rich S et al (1989) Familial clustering of diabetic kidney disease: evidence for genetic susceptibility to diabetic nephropathy. N Engl J Med 320:1161-1165

49. Borch-Johnsen K, Norgaard K, Hommel E et al (1992) Is diabetic nephropathy an inherited complication? Kidney Int 41:719-722

50. Quinn M, Angelico MC, Warram JH et al (1996) Familial factors determine the development of diabetic nephropathy in patients with IDDM. Diabetologia 39:940-945
51. Freedman BI, Tuttle AB, Spray BJ (1995) Familial predisposition to nephropathy in African-Americans with non-insulin-dependent diabetes mellitus. Am J Kidney Dis 5:710-713

52. Canani LH, Gerchman F, Gross JL (1999) Familial clustering of diabetic nephropathy in Brazilian type 2 diabetic patients. Diabetes 48:909-913

53. Fioretto P, Steffes MW, Rich SS et al (1999) Is diabetic nephropathy inherited? Studies of glomerular structure in type 1 diabetic sibling pairs. Diabetes 48:865-869

54. Krolewski M, Eggers PW, Warram JH (1996) Magnitude of endstage renal disease in IDDM: a 35 year follow-up study. Kidney Int 50:2041-2046

55. Rich SS (2006) Genetics of diabetes and its complications. J Am Soc Nephrol 17:353-360

56. Janssen B, Hohenadel D, Brinkkoetter P (2005) Carnosine as a protective factor in diabetic nephropathy: association with a leucine repeat of the carnosinase gene CNDP1. Diabetes 54:2320-2327

57. Freedman BI, Hicks PJ, Sale MM et al (2007) A leucine repeat in the carnosinase gene $C N D P 1$ is associated with diabetic end-stage renal disease in European Americans. Nephrol Dial Transplant 22:1131-1135

58. Al-Kateb H, Boright AP, Mirea L et al (2008) Multiple superoxide dismutase 1 splicing factor serine alanine 15 variants are associated with the development and progression of diabetic nephropathy: the Diabetes Control and Complications Trial/ Epidemiology of Diabetes Interventions and Complications Genetics study. Diabetes 57:218-228

59. Schelling JR, Abboud HE, Nicholas SB, Family Investigation of Nephropathy and Diabetes Research Group et al (2008) Genomewide scan for estimated glomerular filtration rate in multi-ethnic diabetic populations: the Family Investigation of Nephropathy and Diabetes (FIND). Diabetes 57:235-243

60. Gaede P, Lund-Andersen H, Parving HH, Pedersen O (2008) Effect of multifactorial intervention on mortality in type 2 diabetes. New Engl J Med 358:580-591

61. ESPRIT Study (2001) Effect of 3 years of antihypertensive therapy on renal structure in type 1 diabetic patients with albuminuria. Diabetes 50:843-850

62. Rodberg S, Osterby R, Bangstad HJ, Dahlquist G, Persson B (1999) Effect of angiotensin-converting enzyme inhibitor or beta blocker on glomerular structural changes in young microalbuminuric patients with type 1 diabetes mellitus. Diabetologia 42:589-595

63. Cordonnier DS, Pinel M, Barro C et al (1999) Expansion of interstitium is limited by converting enzyme inhibition in type 2 diabetic patients with glomerulosclerosis. J Am Soc Nephrol 10:1253-1263

64. Thallas-Bonke V, Thorpe SR, Coughlan MT et al (2008) Inhibition of NADPH oxidase prevents advanced glycation end product-mediated damage in diabetic nephropathy through a protein kinase C-alpha-dependent pathway. Diabetes 57:460-469

65. Coughlan MT, Forbes JM, Cooper ME (2007) Role of the AGE crosslink breaker, alagebrium, as a renoprotective agent in diabetes. Kidney Int Suppl 106:S54-S60

66. Tuttle KR, Bakris GL, Toto RD, McGill JB, Hu K, Anderson PW (2005) The effect of ruboxistaurin on nephropathy in type 2 diabetes. Diabetes Care 28:2686-2690

67. Ferguson MW, O'Kane S (2004) Scar-free healing: from embryonic mechanisms to adult therapeutic intervention. Philos Trans R Soc Lond B Biol Sci 359:839-850

68. Michalopoulos GK, DeFrances MC (1997) Liver regeneration. Science 276:60-66

69. Leor J, Rozen L, Zuloff-Shani A et al (2006) Ex vivo activated human macrophages improve healing, remodeling, and function of the infarcted heart. Circulation 114(1 Suppl):I94-I100

70. Xu BJ, Shyr Y, Liang X et al (2005) Proteomic patterns and prediction of glomerulosclerosis and its mechanisms. J Am Soc Nephrol 16:2967-2975 